\title{
Challenges of Women Healthcare Providers during Covid-19 Pandemic in Aizawl City, Mizoram, India
}

\author{
Lalrinzuala $^{1}$, H. Elizabeth ${ }^{2}$ \\ ${ }^{1}$ Mphil Scholar, Department of Social Work, Mizoram University, Mizoram \\ ${ }^{2}$ Associate Professor, Department of Social Work, Mizoram University, Mizoram \\ Corresponding Author: Lalrinzuala
}

\begin{abstract}
Background: The onset of the Covid-19 pandemic had a significant influence on people's health, economics, social, and political life. The infection has spread around the world, increasing the stress and challenges faced by healthcare personnel everywhere. Women health workers were actively engaged in the prevention, promotion, and protection of Covid19, holding important positions as doctors, nurses, laboratory technicians, and contributing important role in various other aspects; this virus had an impact on the women health workers' personal lives, mental, physical, and biological health.
\end{abstract}

Aim and Objective: To explore the challenges faced by women health providers confront during Covid-19 pandemic.

Methods: Structured questionnaire was administered among 100 women healthcare providers (nurse, radiographer, laboratory workers) who are working in the different healthcare settings in Aizawl district, Mizoram using online open data kit website. The quantitative data is processed and analysed with the help of Ms Excel and SPSS software.

Results and Conclusion: The study found that women healthcare providers are facing difficulties in balancing work and personal life, adjustment to changes in lifestyle, decrease of interest in work, irregular supply of PPE and fear of exposure. Thus, the respondent suggested continuing working with good supportive equipment's is necessary so as to execute their duties efficiently. The study concludes that effective measures must be taken to ensure safety at workplace.
Keywords: Covid-19 pandemic, challenges, health care providers, workplace safety

\section{INTRODUCTION}

The rapid spread of Covid-19 over the world has resulted in a number of infections and death in both individuals and health workers, the World Health Organization reported 6,287,771 confirmed cases and 379,941 fatalities from the new Coronavirus as of June 3, 2020 and Covid19 infection is also linked to long-term health impacts, in Mizoram the first case of Covid-19 patient was reported on 24 March 2020 who was a returnee from Netherland. The Covid-19 virus epidemic is the greatest since the SARS epidemic in 2003, and the number of reported positives is expanding at a rapid pace. It has resulted in a breakdown of healthcare settings in countries like India and other developing nations, and many healthcare sectors are unable to accept patients since most hospitals are at capacity, and oxygen and ventilators for the dying patient are in short supply. The covid-19 epidemic has had a significant impact on health professionals, since they have experienced a tremendous deal of stress and anxiety, and a huge number of them have been infected with the virus, resulting in a substantial number of deaths among healthcare providers.

\section{LITERATURE REVIEW}

The Covid-19 epidemic has had an impact on nurses' mental health; many are experiencing mental problems such as fear 
and anxiety. Long-term exposure to Covid19 among nurses has resulted in posttraumatic stress symptoms, suicidal ideation, and suicide. Psychiatric intervention is essential to meet the psychological requirements of both health care workers and patients, and adequate mental health assessment and intervention is essential for effective disease control ${ }^{1}$.

The work-life of health-care employees has expanded dramatically as a result of the covid-19 epidemic; excessive workloads, fear of exposure, and dealing with patients' and their families' mental well-being are all challenges for women healthcare providers ${ }^{2}$. Female healthcare professionals have experienced emotional, mental, and social distress as a result of treating Covid -19 patients, the intense working conditions, patient load, and shortage of personal protective equipment have placed a significant strain on female healthcare workers and balancing professional and family life was a challenge ${ }^{3}$.

The threat of illness is the major concern, which has resulted in absenteeism from work, sickness, death, and significant mental distress, which manifests itself in accumulated tension and sleeping difficulties, fear of becoming ill and infecting colleagues and family members ${ }^{4}$. During the spread of Covid-19, healthcare professionals face challenges such as violence against them, long working hours, fear of infection, a lack of personal protective equipment, and psychological effects on themselves and their families ${ }^{5}$.

The Covid-19 epidemic has presented additional problems for healthcare professionals, including lengthy working hours, changes in routine/lifestyle, and the requirement to wear personal protective equipment while they are on duty ${ }^{6}$. The outbreak of Covid-19 in the country caused many problems in healthcare settings and workers. Health care workers are required to work for extended periods of time, which causes mental, physical, and emotional exhaustion, fear of exposure, and discomfort when wearing personal protective equipment for extended periods of time. Inadequate resources and particular curative therapy contribute to the difficulties faced by healthcare personnel. Nurses are required to oversee patients on a regular basis, and because to a lack of nurses in most hospitals, they are required to perform extra work/duty, which places a significant strain on the nurse ${ }^{7}$.

\section{METHODOLOGY}

The primary data was collected by using structured interview schedule and the secondary data was collected through literatures online and offline journals articles. A purposive sampling was adopted to collect the data. The criteria for the sample include women healthcare workers in private and public hospital in Aizawl district, Mizoram. The study was conducted among 100 women healthcare workers in Aizawl district, Mizoram. The quantitative data was collected by using Kobo toolbox an online open data kit website. The quantitative data was processed and analysed with the help of Ms Excel and Statistical Package for the Social Sciences (SPSS).

\section{RESULTS}

Table 1: Background of the Respondents

\begin{tabular}{|c|l|l|c|}
\hline Sl. No. & Characteristics & \multicolumn{1}{|c|}{ Items } & $\mathbf{N}=100$ \\
\hline \multirow{2}{*}{2} & Profession & Medical & $76(76.0)$ \\
\cline { 3 - 4 } & & Para-medical & $24(24.0)$ \\
\hline 2 & \multirow{2}{*}{ Settings } & Private & $62(62.0)$ \\
\cline { 3 - 4 } & & Public & $38(38.0)$ \\
\hline \multirow{2}{*}{3} & \multirow{2}{*}{ Years of experience } & $2-4$ years & $55(55.0)$ \\
\cline { 3 - 4 } & & 5 years and above & $45(36.0)$ \\
\hline
\end{tabular}

The background of the respondents comprises the profession, name of health settings and year of experiences. A maximum of more than half $(76 \%)$ of the respondents are from medical profession. The medical profession includes B.Sc. nursing, auxiliary nursing midwifery and general nursing midwifery and community health workers, whereas less than one third $(24 \%)$ of the respondents are from paramedical profession which includes B.Sc. \& M. Sc. Laboratory Technicians, 
Radiographer and Renal dialysis technologist. The health settings are divided into two sector i.e. private and public, the maximum of more than half $(62 \%)$ of the respondents are from private sector and the remaining of more than one third $(38 \%)$ of the respondents are from public sector. The years of experience of the respondents are classified into two categories, the year of experience shows that a maximum of more than half $(55 \%)$ of the respondents are having an working experience of between 24 years and the remaining of more than one third $(45 \%)$ of the respondents are having an working experience of 5 years and above.

Table 2: Challenges faced during covid-19 pandemic

\begin{tabular}{|c|l|c|}
\hline $\begin{array}{c}\text { Sl. } \\
\text { No. }\end{array}$ & \multicolumn{1}{|c|}{ Items } & Percentage \\
\hline 1 & Difficulty in balancing work and family life & 63 \\
\hline 2 & Work overtime & 56 \\
\hline 3 & Loss of interest & 56 \\
\hline 4 & Gastrointestinal problem & 55 \\
\hline 5 & Fear of exposure & 50 \\
\hline 6 & Changes with lifestyle & 39 \\
\hline 7 & Irregular supply of PPE & 30 \\
\hline \multicolumn{2}{|c|}{ Source Computed } \\
\hline
\end{tabular}

The challenges faced by the women health care providers are identified into 9 items such as difficulty in balancing work and family life, standing for long hours, work overtime, loss of interest, gastrointestinal problem, fear of exposure, low confidence, changes with lifestyle, irregular supply of personal protective equipment. The maximum of the respondents of nearly two-third (63\%) reported that they faced difficulty in balancing work and family life. The respondents of more than half reported that they work overtime and loss their interest at work (56\% each) and where (55\%) of the respondents have encountered gastrointestinal problem. Half $(50 \%)$ of the respondents reported that they are in fear of exposure to virus and nearly half $(40 \%)$ of the respondents have reported that they loss their confidence at work and the other 39\% of the respondents reported that they changed their lifestyle with the outbreak of Covid-19 pandemic. The respondents of nearly one third $(30 \%)$ reported that they are facing difficulty on proper supply of personal protective equipment.

\section{DISCUSSION}

The present study was conducted to explore the challenges faced by women healthcare providers confront during Covid19 pandemic in Aizawl city. According to the findings of this study, women healthcare practitioners face more challenges in managing work and family life than males ${ }^{3}$. The high workload and staff shortage among healthcare professionals as reasons for women healthcare practitioners working extra hours ${ }^{2}$. Many women healthcare professionals are fearful of being exposed to the Covid-19 virus, and they have lost their enthusiasm and interest in their work, as well as in thinking about their health problems ${ }^{4}$. Many women healthcare professionals' lifestyles have been altered as a result of the Covid-19 epidemic; they are no longer able to spend more time with their families and friends, and they must be separated for a period of time as they are in contact with different patients are the hospital ${ }^{4}$. Several institutions have struggled to provide Personal Protective Equipment for female healthcare workers as a result of shortage in supply of personal protective equipment ${ }^{5}$.

\section{CONCLUSION}

Apart from providing curative care, women healthcare workers faced numerous obstacles during the covid-19 pandemic. Women healthcare providers' lifestyles, daily routines, family obligations, and the necessity to work for extended hours at work have all changed as a result of the rise of covid-19 patients. Women healthcare professionals' emotional and psychological well-being is also impacted; they lose interest in their work, have low confidence, and are worried of exposure to the virus. The healthcare system must intervene to provide better facilities and support for women health care providers so that they may work in better conditions and prevent 
Lalrinzuala et.al. Challenges of women healthcare providers during Covid-19 pandemic in Aizawl City, Mizoram, India

physical, mental, and psychological breakdowns.

\section{Acknowledgement: None}

\section{Conflict of Interest: None}

\section{Source of Funding: None}

\section{REFERENCES}

1. Chidiebere Okechukwu E, Tibaldi L, La Torre G. The impact of COVID-19 pandemic on mental healthof Nurses. Clin Ter. 2020;(5):399-400. doi:10.7417/CT. 2020.2247

2. Crimi C, Carlucci A. Challenges for the female health-care workers during the COVID-19 pandemic: the need for protection beyond the mask. Pulmonology. 2021;27(1):1-3. doi:10.1016/j.pulmoe.2020.09.004

3. Shahbaz S, Ashraf MZ, Zakar R, Fischer F. Psychosocial, emotional and professional challenges faced by female healthcare professionals during the COVID-19 outbreak in Lahore, Pakistan: a qualitative study. BMC Womens Health. 2021;21(1): 197. doi:10.1186/s12905-021-01344-y

4. Teixeira CF de S, Soares CM, Souza EA, et al. The health of health professionals in the fight against the Covid-19 pandemic. Ciênc Saúde Coletiva. 2020;25(9):3465-3474. doi:10.1590/1413-81232020259.19562020

5. Vaishya R. Health Care Workers are facing several challenges during COVID-19 pandemic. Published 2020. https://timesofindia.indiatimes.com/readersb $\log /$ newspost/health-care-workers-arefacing-several-challenges-during-covid-19pandemic-dr-prof-raju-vaishya-11529/

6. Gordon A, Lyons C, Rao S, Finoli L. Health Care Workers' Challenges in the Care of a COVID-19 Patient. Crit Care Nurs Q. 2020;43(4):400-406. doi:10.1097/CNQ. 0000000000000325

7. Mehta S, Machado F, Kwizera A, et al. COVID-19: a heavy toll on health-care workers. Lancet Respir Med. 2021;9 (3): 226-228. doi:10.1016/S2213-2600(21) 00068-0

How to cite this article: Lalrinzuala, $\mathrm{H}$. Elizabeth. Challenges of women healthcare providers during Covid-19 pandemic in Aizawl City, Mizoram, India. International Journal of Science \& Healthcare Research. 2021; 6(3): 221-224. DOI: https://doi.org/10.52403/ijshr. 20210738 